Khawla M Awni BDS MSc (Lec.)

\section{The Relationship Between Incisor Crown Shape and Dental Crowding}

\author{
Dept of Pedod, orthod, and Prev Dentistry
}

College of Dentistry, University of Mosul

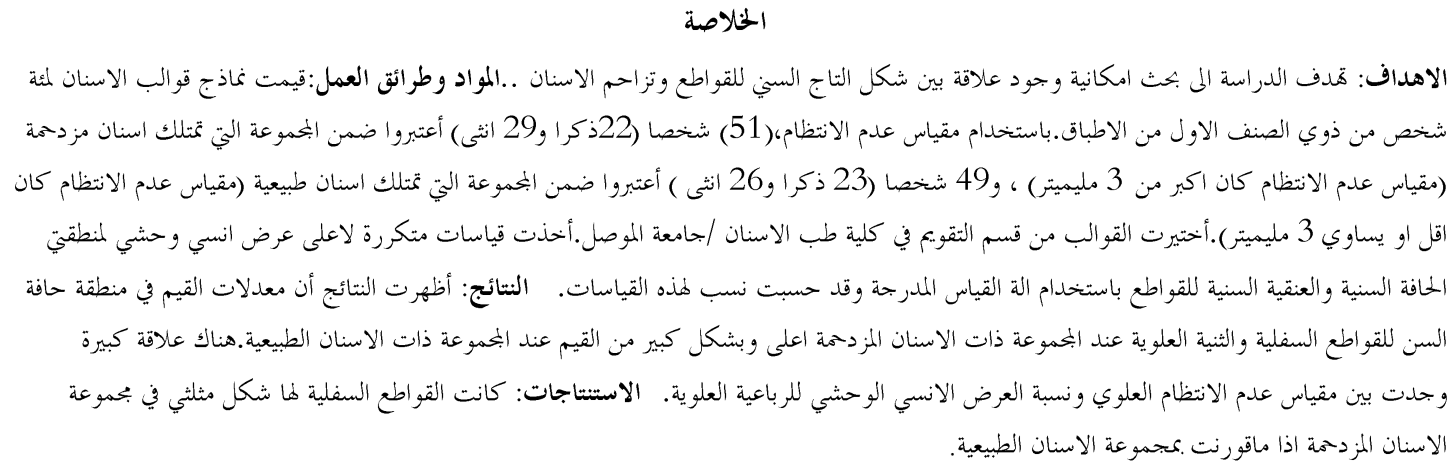

\title{
ABSTRACT
}

Aims: The aim of this study was to investigate if there is a correlation between the shape of the crowns of the incisors and crowding. Materials and Methods: Plaster models of 100 individuals having class I molar relationship were chosen .By using the irregularity index, 51 individuals (22 males and 29 females) were considered to be the crowding group(irregularity index $>3 \mathrm{~mm}$ ), and 49 individuals (23 males and 26 females) were considered to be the normal group(irregularity index $\leq 3 \mathrm{~mm}$ ). The casts were selected from the POP department at the college of dentistry in Mosul University. Repeated measurements of the maximum mesiodistal width of the incisal and cervical areas of the incisors were taken by means of a vernier caliper and a ratios of these measurements were calculated. Results:The mean value for the crowding group was significantly higher in the incisal area of lower incisors and upper central incisors than corresponding values in the normal group. A significant correlation was present between upper irregularity index and upper lateral incisor mesiodistal width ratio. Conclusions: The lower incisors were more triangulary shaped in the crowding group than those in the normal one.

Key words: Incisors, crown shape, crowding.

Awni KM. The Relationship between Incisor Crown Shape and Dental Crowding. Al-Rafidain Dent J. 2012; 12(2): 344-349.

Received: $27 / 4 / 2011$

Sent to Referees: 2/5/2011

Accepted for Publication: 28/6/2011

\section{INTRODUCTION}

The four mandibular incisors are the teeth most prone to positional irregularity. ${ }^{(1)}$ Crowding is a common characteristic of malocclusion. It appears in $37 \%$ of class I malocclusions. Forty percent of children and $85 \%$ of adolescents have some degree of malalignment within the dental arches. ${ }^{(2)}$ Nearly $78 \%$ of the united states population has some degree of anterior dental crowding. ${ }^{(3)}$ Anterior crowding is an orthodontic condition that the puplic considers to be a significant esthetic problem. ${ }^{(4)}$ It affects the labial segment and usually manifests during teenage period.
The etiology is multifactorial such as decrease in dental arch length, maturation and aging of the dentition,mesial drift, soft tissue pressure, pressure from the back of the dental arch, tooth morphology, the amount and direction of late mandibular growth,skeletal structures and complex growth patterns, direction of eruption and degenerative tissue changes. ${ }^{(5,6)}$ Mandibular-incisor-crown morphology is not correlated with the amount of mandibular anterior crowding relapse. ${ }^{(7)}$ Size and shape of tooth crowns are morphogenetically predetermined during embryogenesis by expression of growth factors from enamel 
knots. ${ }^{(8)}$ Malocclusion is the result of either a skeletal or a dental discrepancy, but crowding is a consequence of a tooth size arch-length discrepancy. ${ }^{(9)}$ The prevalence of dental crowding was higher in the anterior region, where as it decreased in the premolar and molar region. ${ }^{(10)}$ The most prevalent malocclusion results from excess tooth size compared with the size of the supporting bone, this creates a tooth-size arch-size discrepancy. ${ }^{(11)}$ Proffit $^{(12)}$ defined tooth size discrepancy as a disproportion among the size of individual teeth .Crowding may be of a genetic origin and might not be caused by excessive tooth size or changes in environmental factors (masticatory activity). ${ }^{(13)}$ Tooth size and crown proportion is only one of the several factors that may be involved in the etiology of dental crowding. ${ }^{(14)}$ The aim of this study was to evaluate if there is a correlation between incisors crown shape and crowding, and to determine the differences between the genders.

\section{MATERIALS AND METHODS}

Upper and lower plaster cast models of 100 individuals were selected from the orthodontic department at college of dentistry in Mosul University. The casts selected had class I molar relationships. By using the Irregularity Index (II) as described by Little, ${ }^{(15)} 51$ individuals (22males and 29 females) were assigned to a crowding group (II $>3 \mathrm{~mm}$ ), and 49 individuals (23 males and 26 females) were assigned to a normal group (II $\leq 3 \mathrm{~mm}$ ). The index is the sum of five measurements, each of which is the linear distance between the anatomic contact points from the mesial aspect of canine to the masial aspect of the contralateral tooth.

In this study, the cervical maximum mesiodistal width (CMD) of each incisor were measured (upper and lower, right and left) at the level of the cementoenamel junction equal to one forth of the labial crown length (Fig 1), as described by You ${ }^{(16)}$ and Ash. ${ }^{(17)}$ The incisal maximum mesiodistal width (IMD) was measured at the level of incisal edge, with the use of a vernier caliper, repeated measurements were taken for the following: 1. L1CMD: Lower central incisor cervical maximum mesiodistal width. 2. L1IMD: Lower central incisor incisal maximum mesiodistal width. 3._L1R: Lower central incisor mesiodistal width ratio (L1IMD/L1CMD $\times 100)$. 4. L2CMD: Lower lateral incisor cervical maximum mesiodistal width. 5 . L2IMD: Lower lateral incisor incisal maximum mesiodistal width. 6. L2R: Lower lateral incisor mesiodistal width ratio (L2IMD/L2CMD $\times 100)$. 7. LIRI: Lower incisor irregularity index.8. U1CMD: Upper central incisor cervical maximum mesiodistal width. 9. U1IMD: Upper central incisor incisal maximum mesiodistal width. 10. U1R: Upper central incisor mesiodistal width ratio (U1IMD/U1CMD $\times 100$ ). 11. U2CMD: Upper lateral incisor cervical maximum mesiodistal width. 12 . U2IMD: Upper lateral incisor incisal maximum mesiodistal width. 13. U2R: Upper lateral incisor mesiodistal width ratio (U2IMD/U2CMD ×100). 14. UIRI: Upper incisor irregularity index. The mean of both left and right measurements were calculated. Analysis of data by using SPSS program was done including descriptive statistics (mean and standard deviations) of the measurements for the crowding and normal groups and t-test between two groups and between males and females. Pearson correlation was done between incisor width ratio, which represents shape, and the irregularity index, which represents crowding. The " $r$ " value is described as significant $P \leq 0.01$ and $P \leq 0.05$ level.

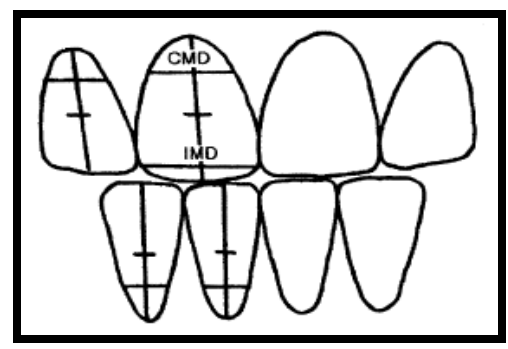

Fig.1: Diagram representing measurements.

\section{RESULTS}

Tables $(1,2)$ described descriptive statistics (means and standard deviations) of the measurements and t-test between normal and crowding groups and between males and females within each occlusion. The results showed that in the total 
sample, the L1IMD, L2IMD, U1CMD, U1IMD and U1Rmeasurements were significantly higher in the crowding group than normal group. In males, L2IMD, U1CMD and U1R were significantly higher in crowding group than normal. Concerning females, U1CMD and U1IMD were significantly higher in crowding group than in normal group. In normal occlusion, males showed significantly higher values of U1IMD, L1R, U1R and
U2R than females, while females showed significantly higher value of L1CMD, U1CMD and U2CMD than males. In crowding occlusion, males showed significantly higher value of L2IMD, L1R and L2R than females. Table (3) showed the Pearson correlation between incisor width ratio and irregularity index. Only a significant correlation was present between $\mathrm{U} 2 \mathrm{R}$ and UIRI.

Table (1): Means and SD of the measurements and t-test between normal and crowding groups in total sample, males and females.

\begin{tabular}{|c|c|c|c|c|c|c|c|c|c|c|}
\hline \multirow[t]{2}{*}{ Variables } & \multirow[t]{2}{*}{ Occlusion } & \multicolumn{3}{|c|}{ Total } & \multicolumn{3}{|c|}{ Male } & \multicolumn{3}{|c|}{ Female } \\
\hline & & Mean & SD & Sig & Mean & SD & Sig & Mean & SD & Sig \\
\hline \multirow{3}{*}{ L1CMD } & $\mathrm{N}$ & 3.507 & 0.501 & NS & 3.337 & 0.55 & NS & 3.65 & 0.40 & NS \\
\hline & $\mathrm{C}$ & 3.601 & 0.509 & & 3.46 & 0.58 & & 3.70 & 0.42 & \\
\hline & $\mathrm{N}$ & 5.461 & 0.402 & $\mathrm{~S}$ & 5.43 & 0.48 & NS & 5.48 & 0.31 & $\mathrm{NS}$ \\
\hline \multirow[t]{2}{*}{ L1IMD } & $\mathrm{C}$ & 5.620 & 0.436 & & 5.65 & 0.46 & & 5.59 & 0.41 & \\
\hline & $\mathrm{N}$ & 158.66 & 24.94 & NS & 167.11 & 30.77 & NS & 151.1 & 15.4 & NS \\
\hline \multirow[t]{2}{*}{ L1R } & $\mathrm{C}$ & 158.82 & 23.39 & & 167.17 & 27.01 & & 152.4 & 18.2 & \\
\hline & $\mathrm{N}$ & 3.658 & 0.509 & NS & 3.52 & 0.50 & NS & 3.77 & 0.49 & NS \\
\hline \multirow[t]{2}{*}{ L2CMD } & $\mathrm{C}$ & 3.629 & 0.486 & & 3.50 & 0.57 & & 3.72 & 0.39 & \\
\hline & $\mathrm{N}$ & 5.957 & 0.402 & $\mathrm{~S}$ & 5.95 & 0.46 & $\mathrm{~S}$ & 5.95 & 0.34 & NS \\
\hline \multirow[t]{2}{*}{ L2IMD } & $\mathrm{C}$ & 6.208 & 0.418 & & 6.33 & 0.39 & & 6.11 & 0.41 & \\
\hline & $\mathrm{N}$ & 165.41 & 22.36 & NS & 171.45 & 24.43 & NS & 160.0 & 19.2 & NS \\
\hline \multirow[t]{2}{*}{ L2R } & $\mathrm{C}$ & 173.89 & 25.27 & & 184.90 & 30.39 & & 165.5 & 16.7 & \\
\hline & $\mathrm{N}$ & 1.373 & 1.169 & $\mathrm{~S}$ & 1.31 & 1.05 & $\mathrm{~S}$ & 1.42 & 1.27 & $\mathrm{~S}$ \\
\hline \multirow[t]{2}{*}{ LIRI } & $\mathrm{C}$ & 8.896 & 3.995 & & 9.46 & 4.54 & & 8.46 & 3.54 & \\
\hline & $\mathrm{N}$ & 6.125 & 0.688 & $\mathrm{~S}$ & 5.79 & 0.70 & $\mathrm{~S}$ & 6.41 & 0.52 & $\mathrm{~S}$ \\
\hline \multirow[t]{2}{*}{ U1CMD } & C & 6.693 & 0.837 & & 6.49 & 0.73 & & 6.84 & 0.88 & \\
\hline & $\mathrm{N}$ & 8.594 & 0.833 & $\mathrm{~S}$ & 8.83 & 0.56 & NS & 8.38 & 0.97 & $\mathrm{~S}$ \\
\hline \multirow[t]{2}{*}{ U1IMD } & $\mathrm{C}$ & 8.922 & 0.568 & & 8.87 & 0.57 & & 8.96 & 0.57 & \\
\hline & $\mathrm{N}$ & 142.01 & 20.76 & $\mathrm{~S}$ & 154.21 & 16.92 & $\mathrm{~S}$ & 131.2 & 17.8 & NS \\
\hline \multirow[t]{2}{*}{ U1R } & $\mathrm{C}$ & 134.88 & 14.87 & & 137.97 & 14.63 & & 132.5 & 14.8 & \\
\hline & $\mathrm{N}$ & 4.594 & 0.628 & NS & 4.33 & 0.56 & NS & 4.82 & 0.59 & NS \\
\hline \multirow[t]{2}{*}{ U2CMD } & $\mathrm{C}$ & 4.566 & 0.692 & & 4.38 & 0.76 & & 4.70 & 0.60 & \\
\hline & $\mathrm{N}$ & 6.699 & 0.606 & NS & 6.73 & 0.55 & NS & 6.66 & 0.65 & NS \\
\hline \multirow[t]{2}{*}{ U2IMD } & $\mathrm{C}$ & 6.770 & 0.786 & & 6.76 & 0.57 & & 6.77 & 0.92 & \\
\hline & $\mathrm{N}$ & 147.79 & 19.88 & NS & 157.52 & 19.68 & NS & 139.1 & 15.9 & NS \\
\hline \multirow[t]{2}{*}{ U2R } & $\mathrm{C}$ & 151.06 & 25.52 & & 157.96 & 25.53 & & 145.8 & 24.6 & \\
\hline & $\mathrm{N}$ & 1.373 & 1.197 & $\mathrm{~S}$ & 1.36 & 1.13 & $\mathrm{~S}$ & 1.38 & 1.27 & $\mathrm{~S}$ \\
\hline UIRI & $\mathrm{C}$ & 9.323 & 4.225 & & 10.31 & 5.44 & & 8.57 & 2.87 & \\
\hline
\end{tabular}

(Measurements in millimeters).

$\mathrm{N}=$ Normal, $\mathrm{C}=$ Crowding, $\mathrm{SD}=$ Standard Deviation, NS=Not Significant, $\mathrm{S}=$ Significant at $P \leq 0.01$ and $P \leq 0.05$. 
Table (2): Means and SD of the measurements and t-test between males and females within normal and crowding groups.

\begin{tabular}{|c|c|c|c|c|c|c|c|c|c|c|}
\hline \multirow{3}{*}{ variables } & \multicolumn{5}{|c|}{ Normal } & \multicolumn{5}{|c|}{ Crowding } \\
\hline & \multicolumn{2}{|c|}{ Males } & \multicolumn{2}{|c|}{ Females } & \multirow[t]{2}{*}{ Sig } & \multicolumn{2}{|c|}{ Males } & \multicolumn{2}{|c|}{ Females } & \multirow[t]{2}{*}{ Sig } \\
\hline & Mean & SD & Mean & SD & & Mean & SD & Mean & SD & \\
\hline L1CMD & 3.33 & 0.55 & 3.65 & 0.40 & $\mathrm{~S}$ & 3.46 & 0.58 & 3.70 & 0.42 & NS \\
\hline L1IMD & 5.43 & 0.48 & 5.48 & 0.31 & NS & 5.65 & 0.46 & 5.59 & 0.41 & NS \\
\hline L1R & 167.11 & 30.7 & 151.19 & 15.4 & $S$ & 167.17 & 27.0 & 152.49 & 18.2 & S \\
\hline L2CMD & 3.52 & 0.50 & 3.77 & 0.49 & NS & 3.50 & 0.57 & 3.72 & 0.39 & NS \\
\hline L2IMD & 5.954 & 0.46 & 5.959 & 0.34 & NS & 6.33 & 0.39 & 6.11 & 0.41 & $S$ \\
\hline L2R & 171.45 & 24.4 & 160.06 & 19.26 & NS & 184.90 & 30.3 & 165.54 & 16.7 & S \\
\hline LIRI & 1.31 & 1.05 & 1.42 & 1.27 & NS & 9.46 & 4.54 & 8.46 & 3.54 & NS \\
\hline U1CMD & 5.79 & 0.70 & 6.41 & 0.52 & $\mathrm{~S}$ & 6.49 & 0.73 & 6.84 & 0.88 & NS \\
\hline U1IMD & 8.83 & 0.56 & 8.38 & 0.97 & S & 8.87 & 0.56 & 8.96 & 0.57 & NS \\
\hline U1R & 154.21 & 16.9 & 131.22 & 17.8 & S & 137.97 & 14.63 & 132.54 & 14.8 & NS \\
\hline U2CMD & 4.33 & 0.56 & 4.82 & 0.59 & S & 4.38 & 0.76 & 4.70 & 0.61 & NS \\
\hline U2IMD & 6.73 & 0.55 & 6.66 & 0.65 & NS & 6.76 & 0.57 & 6.77 & 0.92 & NS \\
\hline U2R & 157.52 & 19.68 & 139.19 & 15.94 & $S$ & 157.96 & 25.5 & 145.82 & 24.6 & NS \\
\hline UIRI & 1.36 & 1.13 & 1.38 & 1.27 & NS & 10.31 & 5.44 & 8.57 & 2.87 & NS \\
\hline
\end{tabular}

(Measurements in millimeters).

$\mathrm{N}=$ Normal, $\mathrm{C}=$ Crowding, $\mathrm{SD}=$ Standard Deviation, NS=Not Significant, $\mathrm{S}=$ Significant at $P \leq 0.01$ and $P \leq 0.05$.

Table (3): Pearson correlation between incisor width ratio and irregularity index.

\begin{tabular}{ccccc}
\hline & L1R & L2R & U1R & U2R \\
\hline LIRI & -0.091 & 0.033 & -0.229 & -0.039 \\
UIRI & 0.106 & 0.165 & -0.087 & $0.305^{*}$ \\
\hline
\end{tabular}

*correlation is significant at the 0.05 level.

\section{DISCUSSION}

In this study, the lower incisors were larger incisally in crowding group than normal group. Incisor crowns comes in many shapes: square, triangular, ovoid and mixed. ${ }^{(16,17)}$ It has been stated that the broader the contact, the more stable the tooth and the less likely it is to slip under pressure or tension. ${ }^{(6)}$ Triangular shaped incisors have a small contact area and thus a more unstable contact. ${ }^{(5,6,18)}$ The results of the present study were similar to those reported by others. ${ }^{(19-21)}$ This study showed that U1CMD and U1IMD in the crowding group were significantly higher than normal group in the total sample and in females, while males had higher value of U1CMD than normal one. Other measurements also higher in crowding group but not to a significant level. ${ }^{(14)}$ Agenter $e t$ $a l .{ }^{(11)}$ stated that crown dimensions were characteristically larger in the sample with crowding. The association between dental crowding and tooth size has been studied previously, various studies have reported a significant association between both, ${ }^{(1,21,}$
22, 23) while others disagree. ${ }^{(24,25)}$ It is expected that tooth sizes is not the only determining factor in the origin of crowding. ${ }^{(14)}$

Rhee et al. ${ }^{(21)}$ stated that the prevalence of crowding is higher in individuals with triangular shaped incisors. The study showed that in the normal group males showed significantly higher values of U1IMD, L1R, U1R and U2R than females, while females showed significantly higher value of L1CMD, U1CMD and U2CMD than males. Some studies stated that there are no significant differences in the incisors tooth size between males and females. ${ }^{(26,27)}$ While others stated that all dimensions are more pronounced in males than females. ${ }^{(28,29)}$ It has been evaluated that a major sex differences in tooth shape emerges, with males tending toward more nearly square dimensions and females have more rounded crowns. ${ }^{(30,}{ }^{31)}$ In crowding occlusion, this study showed that males had significantly higher value of L2IMD, L1R and L2R than females. Some studies showed that the men's teeth 
were larger than the women's, however no measurement was statistically significant. ${ }^{(5,22,28,32,33)}$ Others showed that a statistically significant gender difference was found in anterior ratio. ${ }^{(34,35)}$ Upper central incisor of males is larger than females, while upper lateral incisor of females had a sexually dimorphic crown form characterized by a significantly smaller mesiodistal measurements at the level of the cementoenamel junction, which translated into more flared upper lateral incisor crowns. ${ }^{(36)}$ When male and female measurements were compared, statistical significance was seen in both measurements of L2CMD and L2IMD, and in both U1IMD and U2IMD. Females had more triangulary shaped lower incisors whereas males had more triangulary shaped upper incisors. However these differences were not statistically significant. ${ }^{(21)}$ The results of the current study showed a positive correlation exists between the U2R and UIRI, this result is similar to that found by Rhee et al. ${ }^{(21)}$ which means that more triangulary shaped upper lateral incisor leads to more crowding.

\section{CONCLUSIONS}

The lower incisors were larger incisally in crowding than normal group which means that these teeth are more triangulary shaped and having a small contact area, thus more unstable contacts. The results of the present study suggest that the prevalence of crowding is higher in individuals with triangulary shaped incisors.

\section{REFERENCES}

1. Peck S,Peck H. Crown dimensions and mandibular incisor alignment. Angle Orthod. 1972; 42(2): 148-153.

2. Profft WR. Contemporary Orthodontics. (Korean Edition). Seoul Jisung; 1993.

3.Buschang $\mathrm{PH}$, Shulman JD. Incisor crowding in untreated persons 15-50 years of age: United States,1988-1994. Angle Orthod. 2003; 73: 502-8.

4.Shaw WC, Richmond S, Kenealy PM, Kingdon A, Worthington H. A 20 year cohort study of health gain from orthodontic treatment: psychological outcome. Am J Orthod Dentofacial Orthop. 2007; 132: 146-57.
5. Shah AA, Brook HA. Incisor crown shape and crowding. Am J Ortho Dentofacial Orthop. 2003; 123: 562-7.

6. Richardson ME. The etiology of late lower arch crowding alternative to mesially directed forces: A review. Am J Orthod Dentofacial Orthop. 1994b. 105: 592-597.

7. Defreitas RM, Faria RC, Castro R, Janson G, Freitas SMK, Henriques CFJ. Correlation between mandibular incisor crown morphologic index and postretention stability. Am J Orthod Dentofacial Orthop. 2006; 129: 559-61.

8.Smid JR, Rowland JE, Young WG, Coschigano KT, Kopchick JJ, Waters MJ. Mouse molar dentine size/shape is dependent on growth hormone status. $J$ Dent. Res. 2006; 86: 463-8.

9. Poosti MG, Jalali T. Tooth size and arch dimension in uncrowded versus crowded class I malocclusion. J Contemp Dent Pract. 2007; 8: 45-52.

10. Shigenobu N, Hisano M, Shima S, Matsubara N, Soma k. Patterns of dental crowding in the lower arch and contributing factors. Angle Orthod. 2006; 77(2): 303-310.

11.Agenter KM, Harris FE, Blair NR. Influence of tooth crown size on malocclusion. Am J Ortod Dentofacial Orthop. 2009; 136: 795-804.

12. Proffit WR. Contemporary Orthodontics. 2007; 4th edtion. St. Louse: Mosby. 199 .

13. Mockers O, Aubry M, Mafart B. Dental crowding in a prehistoric population. European J Orthod. 2004; 26(2): 151-156.

14. Bernabe E, Flores-Mir C. Dental morphology and crowding. Angle Orthod. 2006; 76(1): 20-25.

15. Little RM. The irregularity index: a quantitative score of mandibular anterior alignment. Am J Orthod.1975; 68: 554-63.

16. You JD. Dental anatomy. Seoul: Ham hoon; 1982.

17. Ash MM. Wheeler's dental anatomy, physiology and occlusion.7th ed. Philadelphia: WB Saunders; 1993.

18. Bennet JC, Laughlin RP. Orthodontic management of the dentition with the preadjusted appliance (Korean edition). Seoul: Narae: 1998. 
19. Suhr JE.A study of dental crowding and its relationship to mandibular incisor shape by model analysis in adolescents. Korean J Orthod.1994; 24: 24773.

20. Jung MH, Yang WS. Causative factor and predictability of arch length discrepancy. Korean J Orthod.1997; 27: 45771.

21. Rhee SH, Nahm SD. Triangularshaped incisor crowns and crowding. Am $J$ Orthod Dentofacial Orthop. 2000; 118: 624-8.

22. Bernabe E, Biostat C, Villanueva MK, Flores-Mir C. Tooth width ratio in crowded and non crowded dentitions. Angle orthod. 2004; 74(6): 765 768.

23. Smith RJ, Davidson WM, Gipe DP. Incisor shape and incisor crowding: a re-evaluation of the peck and peck ratio. Am J Orthod Dentofacial Orthop. 1982; 82: 231-235.

24. Imai H, Kuwana R, Yonezu T, Yakashiji $M$. The relation between tooth shape ratio and incisor arrangement in Japanese children. Bull Tokyo Dent Coll. 2006; 47(2): 45-50.

25. Glimore CA, Little RM. Mandibular incisor dimensions and crowding. Am J Orthod Dentofacial Orthop. 1984; 86: 493-502.

26. Samir EB, Jakobsen RJ, Essam MA, Garcia FA. Comparisons of mesiodistal and buccolingual crown dimensions of the permanent teeth in three population from Egypt, Mexico and the United States. Am J Orthod Dentofacial Orthop. 1989; 96(5): 416-22.

27. Iyad KA, Zaid BB, Ahmed MH.Tooth size discrepancies among Jordanian school children. European J Orthod. 2008; 30(5): 527-531.

28.Uysal T, Sari Z, Basciflici AF, Memili
B. Intermaxillary tooth size discrepancy and malocclusion: Is there a relation. Angle Orthod. 2005; 75(2): 208-213.

29. Slaj M, Spalj S, Pavlin D, Illes D, Slaj M. Dental arch forms in dentoalveolar class I, II and III. Angle Orthod.2010;80(5):919-924.

30. Doris MJ, Bernard WB, Kuftinec MM.A biometric study of tooth size and dental crowding. Am J Orthod Dentofacial Orthop. 1981; 79(3): 32636.

31. Anderson KM, Behrents RG, Mckinney $\mathrm{T}$, Buschang $\mathrm{PH}$. Tooth shape preferences in an esthetic smile. Am J Orthod Dentofacial Orthop. 2005; 128: 458-65.

32. Mahony OG, Millett TD, Barry KM, Mcintyre TG, Coronin SM. Tooth size discrepancies in Irish orthodontic patients among malocclusion groups. Angle Orthod. 2011; 81(1): 132-135.

33. Oktay $H$, Ulukaya E. Intermaxillary tooth size discrepancies among different malocclusion groups. European $J$ Orthod. 2010; 32(3): 307-312.

34.Strujc M, Ani-Milosevic S, Mestrovic S,Maladen. Tooth size discrepancy in orthodontic patients among different malocclusion groups. European $\mathrm{J}$ Orthod. 2009; 31(6): 584-589.

35. Szulc-Wedrychowska B, OlszowskaJaniszewska J, Stepien P. Over all and anterior Bolton ratio in class I, II and III orthodontic patients. European $J$ Orthod. 2010; 32(3): 313-318.

36. Maxillary incisor crown form and crowding in adolescents orthodontic patients. A thesis presented for the Graduate studies Council, The university of Tennessee, and Health science center by Kortne King Frederick. 2008, PP. 41-119. 